\title{
NO ENTRE DE UMA FORMAÇÃO DOCENTE MENOR
}

Felipe Vargas da Silva ${ }^{1}$

\section{Um pesquisar: travessias}

Como alguém aprende? Uma questão faz com que um corpo-pedagogo em produção se lance em pesquisa. Como nasce uma pesquisa? Questões contíguas se colocam lado a lado para um caminho em travessia.

Como alguém aprende? Uma questão instaura problema num processo de produção de pensamento e produz num corpo-pedagogo um desejo. Algo que não se mensura ou sequer tende a preencher qualquer coisa. Um desejo guia um corpo-pedagogo ao encontro com o ato de pesquisar. Uma pesquisa vem como um processo de produção que teve seu começo numa graduação em Pedagogia. No encontro com a graduação surge um modelo cognitivo representativo que toma o pensamento como algo espontâneo e que se captura com concentração e estudo. O pensamento, dessa forma compreendido, já está pronto e acabado bastando simplesmente que qualquer um venha e tenha acesso a ele. Entender que o pensamento está pronto denuncia uma espécie de dogma, em que se admite uma universalidade e uma atemporalidade.

Em muitos de seus trabalhos, Deleuze denuncia as 3 principais características do modelo da representação, tais como o senso comum, com seu correlato recognição, e/ou o comprometimento do pensamento com a busca de verdades universais e atemporais. Para ele o senso comum seria responsável por construir uma imagem do pensamento - o pensamento dogmático -, na qual este se apresenta como naturalmente propenso ao conhecimento. Ou seja, o senso comum se encarregaria de construir uma representação universalizante do que seria o pensamento (MAURICIO, MANGUEIRA, 2011, p. 293)

Esse movimento de pensamento funciona como um sustentáculo para um movimento de educação que Gallo (2002) atribui como maior e que, junto a uma política de conhecimento representativa, busca levar a produção de uma captura do pensamento. Não permite vazão à invenção, pois sua maquinação atua num processo de indução a um pensamento já existente.

A educação maior é aquela dos planos decenais e das políticas públicas de educação, dos parâmetros e das diretrizes, aquela da constituição e da LDB, pensada e produzida pelas cabeças bem-pensantes a serviço do poder. A educação maior é aquela instituída e que quer instituir-se, fazer-se presente, fazer-se acontecer. A educação maior é aquela dos grandes mapas e projetos (GALLO, 2002, p. 173).

Junto a esse processo de constituição de pensamento, um corpo que se lança ao curso de Pedagogia foi construindo movimentos de saber que sempre causavam uma inquietação. $\mathrm{O}$ que as pesquisas davam como certezas profundas, aquele corpo desconfiava que a coisa não parecia tão óbvia como se dava. Foi então que numa disciplina da graduação aquele corpo em formação se sentiu tentado. Uma questão bem semelhante à sua foi lançada logo na primeira aula de uma das

\footnotetext{
${ }^{1}$ Pedagogo e Mestrando em Educação (2017/2019) pelo PPGE/UFJF Universidade Federal de Juiz de Fora. Orientado pela Prof. Dr. Margareth Ap. Sacramento Rotondo E-mail: felipe.madruga@ hotmail.com.
} 
disciplinas obrigatórias ${ }^{2}$ : como seria um mundo sem matemática? Em um primeiro momento aquela questão se fez muito simples de responder para aquele corpo repleto de saberes sobre o mundo. "Ora, um mundo sem matemática é uma folha em branco, por fim, o que poderia existir sem a matemática?". Quando a professora começou a tornar problema aquela questão, aquele corpopedagogo também entrou em questão. A possibilidade de discutir um mundo representativo e dado ou mundo inventivo a ser criado colocou aquele corpo a pensar no pensamento. Aquela aula foi um convite para uma nova dança. Pensar uma questão cognitiva para além daquilo que vinha se desenhando em curso. A questão “como alguém aprende?" ganha um novo sabor naquele corpo. Aquela pergunta foi como uma rachadura em um muro. Muro esse que já possuía toda uma estrutura marcada por um processo de produção de pensamento que convidava sempre os corpos a um saber universal. Como se ele já estivesse ali, encoberto pelas camadas históricas só esperando que alguém o retirasse todo movimento que o tempo cuidou de esconder.

Uma forma outra de produzir pensamento se instaura e convida um corpo a se aventurar em uma travessia.

Findado o tempo da graduação o corpo-pedagogo lança-se a uma pesquisa no curso de Mestrado em educação pelo PPGE/UFJF. Quando nasce uma pesquisa? Pesquisar vai se constituindo com desejo entre cognições e vai tramando com agulha e linha um movimento de furar e tramar redes.

\section{Agulha - linha: cognição inventiva e educação menor}

- Mas você é orgulhosa.

- Decerto que sou.

- Mas por quê?

- É boa! Porque coso. Então os vestidos e enfeites de nossa ama, quem é que os cose, senão eu?

- Você? Esta agora é melhor. Você é que os cose?

Você ignora que quem os cose sou eu e muito eu?

- Você fura o pano, nada mais; eu é que coso, prendo um pedaço ao outro, dou feição aos babados...

- Sim, mas que vale isso? Eu é que furo o pano, vou adiante, puxando por você, que vem atrás obedecendo ao que eu faço e mando...

Machado de Assis

Dois conceitos se entrelaçam, vão furando, tecendo e cosendo uma pesquisa. Aprendizado vai se constituindo com formação. Como corpos lançados a processos formativos engendram para si mundos? Como engendram cognição? A cognição inventiva não se confunde com algo espontâneo ou intuitivo, como se fosse um processo de captura a esmo. Ela se constitui num ato de repetição que tende a ir tornando os corpos outra coisa diferente do que se é.

A cognição inventiva não é o mesmo que cognição espontânea. Embora a invenção não seja privilégio de grandes artistas ou cientistas, mas seja distribuída por todos e por cada um, ela depende de cultivo. A invenção não vai por si, mas envolve repetição. (KASTRUP, 2005, p. 1279).

\footnotetext{
2 Disciplina intitulada de Fundamentos teóricos metodológicos do ensino de Matemática I ministrada pela professora Drt. Margareth Aparecida Sacramento Rotondo.
} 
Um movimento de cognição inventiva atua num campo relacional de forças onde subjetividade e objetividade são constantemente produzidos. Elas são inventadas a partir de relações e sempre constituem e se constituem numa territorialização precária. Estão sempre passíveis de modificações e de novas invenções. O tempo na cognição inventiva não é compreendido de forma universal, linear. O conhecimento só é engendrando quando o corpo se encontra com ele numa relação intrínseca e extrínseca. Linhas de força vão sempre se relacionando e compondo uma rede infinita de conexões. Os pontos vão se relacionando de uma forma não linear.

O si e o mundo são co-engendrados pela ação, de modo recíproco e indissociável. Encontram-se, por sua vez, mergulhados num processo de transformação permanente. Pois ainda que sejam configurados como formas, estas restam sujeitas a novas perturbações, que forçam sua reinvenção (KASTRUP, 2005, p. 1276).

Esse modo de produzir conhecimento engendra novas possibilidade de compor uma das questões que dispara essa pesquisa: “como alguém aprende?”. Se o mundo não está dado, quais os movimentos que um professor pode fazer para junto aos alunos produzir conhecimento? Como alunos junto aos seus professores podem inventar mundos e se inventarem a partir da produção de conhecimentos? Como - num sentido modal - pensar o "que pode o menor"?

Outro conceito que vai cosendo essa pesquisa está vinculado ao menor. Menor aqui não entendido enquanto em seu sentido pejorativo. Não compreende uma desvalorização em relação ao maior e nem se pretende tornar maior. Menor aqui ocupa um lugar que se dá no entre das relações. Quando se pensa num currículo estipula-se um caminho já traçado. Quais são as banalidades que se constituem nesse caminho? Como o fio que escapa da agulha e faz tremer um regime já instaurado? E como uma formação acontece transversalmente, rompendo com a lógica horizontal e vertical?

Uma educação menor faz jogo no interstício. Atua no fora não se deixando capturar pelas formas preestabelecidas. O menor não preocupa, ele se ocupa com. Uma educação menor possui um vínculo com o cultivo de si. Engendra sentidos outros nas significações já embutidas nos movimentos maiores. Um curso de Pedagogia possui suas possibilidades demarcadas, mas o que acontece quando nada acontece? Qual movimento faz abalar configurações de forças desestabilizando-as e abrindo caminho para novas experimentações?

Políticas cognitivas inventivas e educações menores vão cosendo uma pesquisa.

\section{Cartografias de uma sala de aula de mestrado}

Numa sala de aula de curso de mestrado, a questão que dera início a esse movimento de pesquisa acompanhada de novos sabores e de novas configurações vai se ampliando em conexões e vai ganhando um corpo. Junto à experiência de estar na pós- graduação vem um movimento de fazer das salas de aula do mestrado a produção com os resíduos decalques. Mapeamentos das linhas de força que vão constituindo aquele espaço poderiam dar vazão a um processo de formação? Aprende-se somente quando um professor explica uma temática ou o modo como ele se porta frente a uma pergunta também produz formação?

Uma sala de aula está repleta de multiplicidades. Nunca se sabe de antemão o que vai surgir e tão pouco se prevê os movimentos que vão se constituir. Traremos aqui dois acontecimentos em uma mesma aula, porém com jogos distintos forças. O movimento que se constituiu nos dois episódios propõe decalques dos distintos modos de ser docente e dos 
distintos movimentos empregados em um ato de perguntar. Quem comanda a aula, professor ou aluno? Podem ser os dois?

\section{Caso 1}

Em uma manhã num encontro de uma disciplina do curso de mestrado da UFJF um professor inicia sua aula. Havia uma combinação anterior de uma apresentação de um texto previamente escolhido pelo professor.

- Bom dia meninos e meninas. Como ficou combinado vamos hoje discutir o texto sobre educação jesuítica e dar início ao nosso curso, bom, nem tão início assim né? Podemos dizer que já iniciamos, pois na semana passada assistimos a um documentário que tratava da questão da História nova. Alguém tem alguma colocação a fazer? Ninguém?

Num primeiro momento a turma parecia um tanto receosa em falar, aquele momento inicial se fizera muito frustrante e ninguém se atreveu a iniciar a fala. O professor, ansioso para que aula tivesse seu começo e tendo em vista a negativa da turma em se pronunciar bradou com um largo sorriso:

- Bom! Já que ninguém tem nada a dizer, "bora” apresentar o texto?!

Quando tudo dava indícios de que a aula se iniciaria, uma voz doce e veloz, um corpo girante numa cadeira e um dedo para o alto chama atenções para si com um pedido:

- Espere um pouco, preciso tempo para falar sobre o vídeo. Tenho coisas a dizer, mas não sei o que dizer agora. Preciso de mais tempo....

O professor meio que surpreso com a abordagem de relance sacou a cadeira que estava em sua frente, posicionou-a em frente à garota que houvera feito a pergunta e sentou-se como se esparramasse e já bem alocado na cadeira dispara:

- Então vamos lá, diga-me o que te aflige!

Aquele gesto despertou risos em alguns e conforto para outros. Parecia que muitos queriam ter tido a coragem daquela garota, mas não tiveram. Ela então deu início a uma discussão que movimentou aquela manhã.

- O que nós queremos? Que morra em educação?

Essa questão foi como uma agulha perfurando pensamentos. Até mesmo a própria postura da garota já havia sido como uma agulha, abrindo caminhos novos para aquela manhã. Manhã que teve pergunta e morte e texto e professor e alunos e planejamentos e e e...

\section{Caso 2}

Em uma manhã num encontro de uma disciplina do curso de mestrado da UFJF um professor inicia sua aula. 
- Bom dia! Hoje daremos início ao nosso curso de metodologias de pesquisa. Eu serei o professor de vocês nessa jornada e trabalharemos com os as perspectivas científicas e filosóficas variadas a fim de que possamos aproveitar melhor nossa passagem por aqui. Pra começar eu gostaria de ouvi-los. Saber o que os trouxe até aqui, quais caminhos trilharam e quais desejos movimentam as pesquisas de cada um. Vamos começar? Podemos começar assim: Digam o nome, curso e expliquem um pouco do projeto de vocês, assim vou tecendo considerações sobre o que podemos fazer, ok? Então vamos!

O professor fez um convite para que todos os que estavam ali dissessem algo sobre sua pesquisa. Muitas falas foram proferidas, no entanto, uma se sobressaiu em relação às outras. A mesma menina que perfurou pensamentos na aula de terça voltou a dar o ar da graça e convidou a todos que estavam ali para dançar.

- Meu projeto já não é mais o que vou pesquisar sabe? Já se torceu e o que me trouxe até aqui parece que não cabe mais. Estou em busca de algo!

- Mas você deve se apressar, pois o mestrado é muito curto e não sobra muito tempo para questões triviais, você deve se apressar!

- Mas um tempo é preciso para que as coisas cheguem ao seu lugar. Gosto de ouvir o que as coisas têm a me dizer. Prefiro ouvi-las a força-las a dizer algo. E acho que preciso ouvir mais coisas para que eu possa dizer delas.

- Eu sei! Entendo tudo isso. Mas existem prazos e metas que não podem esperar demais. Você tem? a qualificação, tem as disciplinas, tem os eventos. Sei que todos têm um tempo diferente, mas você não pode esperar passar demais, senão acaba não dando conta. A qualificação é um ano e você tem de estar preparada

A garota interrompe o professor...

- Então, mas eu não sei nem ainda qual linguagem vou utilizar na minha qualificação, talvez venha algo novo.

O professor meio incomodado com a fala da garota diz:

- Mas é claro que você sabe a linguagem que vai utilizar, o programa pede uma linguagem específica. Vou te explicar não se pode abandonar a tradição. O novo não se faz do nada, tem uma linha a seguir.

- Eu não disse que não vou deixar de seguir alguma linha só disse que não sei qual linguagem vai vir, eu preciso de tempo para me envolver com essas coisas e não quero utilizar uma linguagem tradicional só por que tenho que segui-la. Eu ainda não sei o que vou fazer.

- Mas quando se entra está submetido às normas e às tradições. Você precisa segui-las para depois pensar em utilizar outras coisas.

- Mas eu ainda não sei! Eu preciso de tempo e você não está me escutando. Não quero mais falar. 
O diálogo foi mais um embate do que propriamente um diálogo. De um lado alguém que precisa de tempo e do outro alguém que parecia ser o senhor do tempo. Muitas verdades e imposições e tradições e linguagens e vidas foram atravessadas com aquelas falas. Agulha e linha cosendo pesquisa.

Encontros em uma sala de aula de um curso de mestrado engendram inquietações em um corpo pesquisador. Entre políticas cognitivas representativas e inventivas, entre planejamentos e encontros, uma formação vai se cosendo. Assim como agulha e linha, professores e alunos, lançados ao movimento de salas de aula, vão produzindo vida. Imagens pré-estabelecidas anteriores às relações, forças vão se chocando e promovendo encontros de forças... formação menor!

\title{
O que acontece no entre: invenções
}

Corpos lançados a um curso de pós-graduação em Educação. Corpos lançados a estipulações prévias, o que pode acontecer? O que pode? Pode o aluno começar uma aula? Quando uma aula começa? Modos docentes de ser, modos discentes de ser, algo a esperar? O que pode modos docentes-discentes de ser não antecipáveis? Pode?

Um modo maior estípula um movimento: estudo de um texto e comentários sobre o filme. Um território estriado, marcado e já antecipado (Maior) a um jogo de forças encontra resistência (menor). Uma aula se iniciaria quando o professor começa a falar ou já se iniciou antes com as inquietações da aluna? Um modo maior opera com forças já estabelecidas, com movimentos já capturados que tentam induzir e até mesmo roubar o pensamento do outro através da aproximação da identidade. Deleuze (2009) denomina essa estrutura de captura de recognição.

\begin{abstract}
Assim, através da recognição, o pensamento - representacional - se caracterizará por tecer com o mundo uma relação que tem por objetivo principal reconhecê-lo, ou seja, uma relação puramente contemplativa. Esta contemplação seria feita por um pensador que se apoiaria em valores transcendentes universais, buscando atingir a verdadeira natureza das coisas, sua identidade, sua essência. Desse modo, a recognição nos permitirá atingir o elemento principal do modelo da representação para Deleuze: a identidade (MAURICIO e MANGUEIRA, 2011, p. 294).
\end{abstract}

O modo maior opera por recognição. A recognição opera com a representação. Quando o professor faz a pergunta ele anseia por uma resposta. Um jogo onde se espera algo, onde comentários devem surgir. Quando o silêncio se faz presente e o professor se movimenta para o caminhar de sua aula uma força se faz agulha. Devir-agulha no corpo-aluna. A questão que a aluna engendra faz um furo na malha representativa. $\mathrm{O}$ ato engendrar pensar no pensamento faz-se como agulha tanto no professor quanto na aluna. Enquanto uma ansiava por mais tempo o outro, com urgência em não o perde-lo, quis correr.

A questão fez se na aluna quando o professor deu fim ao movimento de sua pergunta para iniciar outro movimento na aula. O professor ansiava por pensamentos e o que se deu foi o ato de pensar da aluna. Algo que foge do esperado e ganha fluxo em um ato de pensar da aluna.

O que é primeiro no pensamento é o arrombamento, a violência, é o inimigo, e nada supõe a Filosofia; tudo parte de uma misosofia. Não contemos com o pensamento para fundar a necessidade relativa do que ele pensa; contemos, ao contrário, com a contingência de um encontro com aquilo que força a pensar, a fim de erguer e estabelecer a necessidade absoluta de um ato de pensar, de 
uma paixão de pensar. As condições de uma verdadeira crítica e de uma verdadeira criação são as mesmas: destruição da imagem de um pensamento que pressupõe a si próprio, gênese do ato de pensar no próprio pensamento (DELEUZE, 2009, p. 203).

O fim do tempo forçou na aluna um movimento que fez o professor se acomodar na cadeira e acompanhar o fluxo ao qual foi convidado a entrar. "Espere um pouco, preciso tempo para falar sobre o vídeo. Tenho coisas a dizer, mas não sei o que dizer agora. Preciso de mais tempo....". Várias coisas poderiam acontecer, várias reações poderiam se instaurar: deu-se o professor junto ao movimento. Uma composição se fez! Professor-aluna-cadeira-sala de aula, tudo junto. Uma pergunta e um pedido de tempo fazendo-se agulha e linha. Quem cose? Quem conduz? Quem vai primeiro é o mais importante?

- Mas você é orgulhosa. ${ }^{3}$ - Decerto que sou. - Mas por quê? - É boa! Porque coso. Então os vestidos e enfeites de nossa ama, quem é que os cose, senão eu? - Você? Esta agora é melhor. Você é que os cose? Você ignora que quem os cose sou eu e muito eu? - Você fura o pano, nada mais; eu é que coso, prendo um pedaço ao outro, dou feição aos babados... - Sim, mas que vale isso? Eu é que furo o pano, vou adiante, puxando por você, que vem atrás obedecendo ao que eu faço e mando... idem

No jogo da invenção não há melhor ou pior, há sempre composição. A vida nunca é o que se espera dela, mas sim sempre o que acontece. Num encontro em sala de aula nem professor nem aluno são melhores ou mais necessários, são sempre enquanto acontecimentos e produções e invenções e e e....

No segundo caso também encontramos um embate de forças. Por mais que o maior queira se instaurar e capturar ele sempre é também uma relação de forças. Não há nada que não seja relações de força.

Só há visão perspectiva, só há 'conhecimentos perspectivos; e quanto mais deixamos os sentimentos entrarem em consideração a respeito de alguma coisa, quanto mais sabemos incorporar novos olhos, olhos diferentes para essa coisa, mais nosso conceito desta coisa, nossa 'objetividade' será completa. Eliminar a vontade, afastar os sentimentos de exceção, supondo que isso fosse possível, não seria castrar o intelecto? (NIETZSCHE, 1999, p. 202).

O maior nada mais é do que um jogo de forças relacionais já estruturado. O menor atua como aquilo que ainda não foi capturado. É sempre um devir. Devir-agulha no corpo-aluna e no corpo-professor devir-linha no corpo-aluna e no corpo-professor:

- Meu projeto já não é mais o que vou pesquisar, sabe? Já se torceu e o que me trouxe até aqui parece que não cabe mais. Estou em busca de algo!

- Mas você deve se apressar, pois o mestrado é muito curto e não sobra muito tempo para questões triviais, você deve se apressar!

- Mas um tempo é preciso para que as coisas cheguem ao seu lugar. Gosto de ouvir o que as coisas têm a me dizer. Prefiro ouvi-las a forçá-las a dizer algo. E acho que preciso ouvir mais coisas para que eu possa dizer delas.

\footnotetext{
${ }^{3}$ ASSIS, M. de. Um apólogo. Disponível em: 〈http://www.biblio.com.br/conteudo/MachadodeAssis/umapologo.htm>. Acessado em: 29/06/2017.
} 
- Eu sei! Entendo tudo isso. Mas existem prazos e metas que não podem esperar demais. Você tem a qualificação, tem as disciplinas, tem os eventos. Sei que todos têm um tempo diferente mas você não pode esperar passar demais, senão acaba não dando conta. A qualificação é em um ano e você tem de estar preparada.

Forças em confronto. Um corpo pede por mais tempo e um outro corpo incita um tempo a ser seguido. Um corpo em busca de um tempo a fim de dar ouvidos as coisas e um outro corpo induzindo sentido as coisas em detrimento de um tempo a ser seguido. Uma pesquisa em educação se cosendo entre agulhas e linhas e professores e alunos e tempos e... e... e....

Em uma pesquisa em educação, cognição inventiva e recognição vão se constituindo em espaços relacionais. Sala de aula se constituindo enquanto máquina hidráulica "teria um modelo hidráulico, ao invés de ser uma teoria dos sólidos, que considera os fluidos como um caso particular; com efeito o atomismo antigo é indissociável dos fluxos, o fluxo é a realidade mesma ou a consciência" (DELEUZE; GUATARRI, 2012, p. 25), máquina de fluxos lentos e rápidos, contíguos e díspares. Enquanto o professor tenta dar manutenção em um jogo de forças, uma aluna busca nos devires movimentos que possam compor uma pesquisa. Esses fluxos vão dando passagens a outras linguagens e outras forças. Um modo maior tenta instaurar e instituir forças já combinadas: - Mas você deve se apressar, pois o mestrado é muito curto e não sobra muito tempo para questões triviais, você deve se apressar! Um modo menor pede passagem como um filete d'agua inventando fluxos e fugas. - Mas um tempo é preciso para que as coisas cheguem ao seu lugar. Gosto de ouvir o que as coisas têm a me dizer. Prefiro ouvi-las a força-las a dizer algo. E acho que preciso ouvir mais coisas para que eu possa dizer delas. Um modo maior reage para que o instaurado seja alcançado, para que uma forma seja reconhecida e reafirmada num corte de fluxos: - Eu sei! Entendo tudo isso. Mas existem prazos e metas que não podem esperar demais. Você a qualificação, tem as disciplinas, tem os eventos. Sei que todos têm um tempo diferente, mas você não pode esperar passar demais, senão acaba não dando conta. A qualificação é um ano e você tem de estar preparada. Um modo menor foge como um garoto que se diverte com suas invenções: - Então, mas eu não sei nem ainda qual linguagem vou utilizar na minha qualificação, talvez venha algo novo. Um modo maior tenta não estremecer frente as oscilações que a máquina hidráulica provoca: - Mas quando se entra está submetido às normas e às tradições. Você tem que as seguis para depois pensar em utilizar outras coisas. Um modo menor escava, roça, remexe, balança, alisa todo e qualquer território que se atreva instaurar: $O$ professor meio que surpreso com a abordagem de relance sacou a cadeira que estava em sua frente, posicionou-a em de frente a garota que houvera feito a pergunta e sentouse como se esparramasse e já bem alocado na cadeira dispara.

Formações vão se inventando num fluxo múltiplo e contínuo. Forças vão se chocando no calor dos encontros e promovendo formação. Corpos lançados ao entre de uma sala de aula encontram forças nas linhas de fugas que se desenham. Desenham e são desenhadas, inventadas, rasuradas.

Corpo lançado à sala de aula cartografa os eixos e as coordenadas das forças que constituem um campo. Forças engendradas em uma relação entre o instituído e o inventado. Toda forma requer uma relação de forças. Para que a forma se modifique as relações também têm de ser diferentes. Quando professores e alunos se encontram, a forma esperada (Maior) com suas relações imbricadas, tendem a querer dar manutenção nas relações. Outras coordenadas podem ser inventadas em uma sala de aula dando início a um processo de produção de coordenadas e eixos outros que não se permitem capturar. Eles cortam o fluxo e dão início a outros fluxos também precários e provisórios. 


\section{(In)conclusões}

Corpo-professor e corpo-aluno e corpo-pesquisador sem encontram numa sala de aula. Encontros vão constituindo formações e produzindo novas formas de ser professor e de ser aluno e de ser pesquisado e e e... Múltiplas potências se constituem em virtualidades sempre em vias de tornar-se. Corpos lançados ainda não eram até que se encontram. Afastando-se das coordenadas prévias, a produção de subjetividade faz-se com torções dessas formas. Um modo docente se entrega ao convite da aluna. Um modo docente afirma uma forma e evoca uma tradição para sustentar sua força. Um modo docente se entrega aos fluxos e convites da aluna. Um modo docente tenta conformar um corpo-aluna as linguagens previamente existentes. Um modo aluna se inventa em busca de linguagens e tempos. Um modo aluna escapa a linguagens prévias e busca com invenção outras linguagens. Um modo aluna inventa outros modos de se fazer aula.

Uma pesquisa vai se tramando em uma sala de aula de um curso de mestrado. Como agulha e linha forças vão sendo tramadas perfurando e dando liga num movimento sempre contínuo. Entre cognições inventivas e formações, cartografias vão se compondo em decalques num jogo de forças que nunca cessam de se produzir. Ora lenta ora rápida, as coordenadas vão se produzindo em múltiplas potências.

Cartografar as forças se faz como acompanhamento de processos.

A processualidade se faz presente nos avanços e nas paradas, em campo, em letras e linhas, na escrita, em nós. A cartografia parte do reconhecimento de que, o tempo todo, estamos em processos, em obra. O acompanhamento de tais processos depende de uma atitude, de um ethos, e não está garantida de antemão. Ela requer aprendizado e atenção permanente, pois sempre podemos ser assaltados pela política cognitiva do pesquisador cognitivista: aquele que se isola do objeto de estudo na busca de soluções, regras, invariantes. $\mathrm{O}$ acompanhamento dos processos exige também a produção coletiva do conhecimento. Há um coletivo se fazendo com a pesquisa, há uma pesquisa se fazendo com o coletivo (BARROS; KASTRUP, 2015, p. 73).

Pesquisa se faz em travessias num campo de produções em processualidades.

A produção dos dados é processual e a processualidade se prolonga no momento da análise do material, que se faz também no tempo, com o tempo, em sintonia com o coletivo. Da mesma maneira, o texto que traz e faz circular os resultados da pesquisa é igualmente processual e coletivo, resultado dos muitos encontros. (BARROS; KASTRUP, 2015, p. 74).

Um pesquisar se constituindo em muitos e com muitos. Em tempos e com tempos. Docentes e discentes e pesquisadores se constituindo em muitos.

\section{Referências}

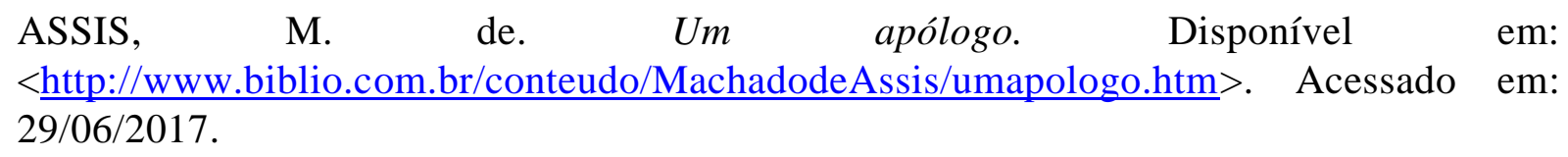


BARROS, L. P.; KASTRUP, V. Pista 3: Cartografar é acompanhar processos. In PASSOS, E.; KASTRUP, V.; ESCÓSSIA, L. da. Pistas do método da cartografia: Pesquisa-intervenção e produção de subjetividade (Org.). Porto Alegre: Sulina, 2015.

DELEUZE, G. Diferença e repetição. São Paulo: Graal, 2009.

DELEUZE, G. GUATARRI, F. Mil platôs: capitalismo e esquizofrenia. v. 5. Rio de Janeiro: Ed. 34, 2012.

GALLO, S. Em torno de uma educação menor. Educação e Realidade. 27 (2) jul./dez. 2002. p. 169-178.

KASTRUP, V. Políticas cognitivas na formação do professor e o problema do Devir-mestre. Educação e Sociedade. Campinas, v. 26, n. 93, set./dez. 2005. Disponível em: <http://www.cedes.unicamp.br>. Acesso em: 20/06/2017.

MAURICÍO, E. MANGUEIRA, M. Imagens do pensamento em Gilles Deleuze: representação e criação. Revista de Psicologia, v. 23, n. 2, maio/ago. 2011. p. 291-394.

NIETZSCHE, F. Genealogia da Moral. Tradução de Paulo César de Souza. São Paulo: Companhia das Letras, 1999. 